\title{
Marcas da colonização da língua oral na educação dos surdos no Brasil: uma questão de preconceito?
}

\author{
Ruth Maria Rodrigues Garé* \\ Márcia Aparecida Amador Mascia**
}

\begin{abstract}
Resumo
Este artigo tem por objetivo discutir a relação da escrita como marca da colonização da língua oral, problematizando se a exigência do domínio de uma escrita normativa do português para os surdos converge ou não para um preconceito linguístico. Ao se desprezar o texto escrito na gramática da Língua de Sinais, a escritura, enquanto, modo de constituição do sujeito pela linguagem, é deixada de lado. Pretende-se empreender uma pesquisa bibliográfica, que tomará como pano de fundo os escritos de Bagno (2011) e Foucault (2010) em especial, para provocar uma reflexão em torno da questão da alteridade na educação dos surdos.
\end{abstract}

Palavras-chave: Surdo; Alteridade; Preconceito.

\section{Les marques de la colonisation du langage oral dans l'éducation des sourds au Brésil: une question de préjugés?}

\section{Résumé}

Cet article vise à discuter de l'éducation des sourds au Brésil et la relation de l'écriture comme une marque de la colonisation de la langue orale, se demandant si l'exigence d'un domaine normatif écrit portugaise pour les personnes sourdes ou non convergent vers un préjugé linguistique. Parce que en ignorant le texte écrit dans la grammaire de la langue des signes, l'écriture, tandis que, la constitution afin que le sujet par le langage, est annulée. Il est prévu de procéder à une revue de la littérature, qui se tiendra le contexte des écrits de Bagno (2011) et Foucault (2010), en particulier, pour provoquer une réflexion sur la question de l'altérité dans l'éducation des sourds.

Mots clés: Sourds; l'altérité; Préjugés.

\section{Introdução}

Este artigo é fruto de uma pesquisa de Pósdoutorado. Esta, por sua vez, nasce a partir das discussões oriundas da Tese de doutoramento, que buscou discutir a produção das identidades dos sujeitos surdos em contextos formais e não formais de educação. Durante o doutoramento, para refletir sobre tal produção, foi preciso uma grande pesquisa teórica, que suscitou inclusive, uma discussão sobre o caráter colonizador da língua portuguesa sobre a comunidade falante de Libras. Por isso, a ideia de fazer um recorte e discutir a escrita surda para além da organização gramatical e sua distância entre o padrão culto do português pareceu ser bem produtiva, pois o que se tem presenciado nas discussões acadêmicas é, de fato, como ensinar português ao surdo. As questões aqui suscitadas são, portanto, advindas do doutorado, que nos direcionou ao pós-doc (doutorado) para dar continuidade à pesquisa no que tange à produção escrita dos surdos.

\footnotetext{
*Endereço Eletrônico: daninasc@yahoo.com.br

***Endereço Eletrônico: silviawolff@bol.com.br
}

Isto posto, o objetivo deste artigo é discutir como exigir do surdo uma produção textual que possa refletir sua compreensão e expressão de ideias sem, no entanto, preencher os mesmos critérios estruturais e formais de um falante/ouvinte de português. O presente texto se inicia com uma breve retomada do processo de educação dos surdos no Brasil, apresentando parte da legislação vigente que consideramos de suma importância para o direcionamento das políticas públicas no que tange à educação dos surdos; em seguida, propõe-se mostrar como se tem delineado a educação atual e a necessidade de se repensar novos modos de avaliação da produção textual do surdo.

\section{Como tudo começou: na colonização portuguesa}

Embora não seja nossa intenção fazer um longo relato sobre a educação dos surdos no Brasil, precisamos lembrar que a educação do surdo, atualmente, está relacionada com a própria concepção de educação implantada no período em 
que o Brasil era organizado segundo a ótica do país colonizador. Assim, a preocupação com a educação do surdo em nosso país só aparece no Segundo Império, cujos relatos históricos tentam dar conta que isso tenha acontecido pela existência de surdos na família real. Então, com a chegada do educador francês Hernest Huet, um ex-aluno do instituto de Paris, que trouxe o alfabeto manual francês e a Língua Francesa de Sinais, a educação do surdo começa sua caminhada no Brasil. Huet, com a ajuda do então imperador, fundou em 26 de setembro de 1887, o Instituto Nacional de Educação dos Surdos (INES). Outras instituições foram fundadas ao longo das décadas e, entre elas, o Instituto Educacional de São Paulo - IESP, em 1954, sendo doado em 1969 para a PUC/SP, sendo atualmente referência para as pesquisas no campo da deficiência auditiva.

Até 1970, a filosofia educacional que permeava a educação dos surdos era voltada ao Oralismo. A Comunicação Total, ainda na abordagem oralista, passa a ser também difundida a partir da visita da educadora Ivete Vasconcelos, da Universidade de Gallaudet. Atualmente, as filosofias educacionais ainda convivem, paralalemente, no Brasil, mas o Bilinguismo tem sido mais utilizado, ou seja, a Língua de Sinais Brasileira como língua primeira do surdo e a Língua Portuguesa como segunda língua.

À luz desses posicionamentos educacionais, rapidamente, aqui relembrados, podemos refletir em que cenário social e político foi se configurando a legislação desde 1916 até os nossos dias. O Código Civil Brasileiro, de $1^{\circ}$ de Janeiro de 1916 , na sua lei $3.071, \S 5^{\circ}$ - III concebe os Surdos-Mudos ${ }^{1}$ como pessoas incapazes de expressarem suas opiniões. Pensar nesta lei nos remete à reflexão de que, apesar de ultrapassada pelos seus 99 anos, foi capaz de deixar uma marca preconceituosa e que produziu o estigma de que Surdo é Mudo, sendo assim, até os nossos dias, já que muitos ainda acreditam que sejam incapazes de se expressarem como um ouvinte/falante da língua oral. $\mathrm{Na}$ contramão também encontramos quem acredite que o surdo que faz leitura labial e aprende a falar é fluente na língua oral, especialmente no registro escrito do português, o que nem sempre é verdade, como será discutido.

Já a Constituição de 1988, em seu artigo 208, inciso III, determina que "o dever do Estado com a educação será efetivado mediante a garantia de atendimento educacional especializado aos portadores $^{2}$ de deficiência, preferencialmente ${ }^{3}$ na rede regular de ensino". O termo portador que foi tão difundido, principalmente entre 1986 e 1995 está sendo aos poucos abandonado, sendo preferível o termo pessoa com deficiência (SASSAKI, 2002). Já o termo preferencialmente, não garantiu e nem garante o acesso, de mais de seis milhões de surdos, segundo Capovilla (2009, p.24).

A Declaração de Salamanca foi um marco decisivo em direção à Educação Inclusiva, no sentido de dar às pessoas deficientes o direito de estudar junto com todos os ditos "normais".

Em 1977 é fundada a FENAIDA Federação Nacional de Educação e Integração dos Deficientes Auditivos, integrada apenas por pessoas ouvintes; em 1983 a Comunidade Surda avança em sua luta por seus direitos, é criada uma Comissão de Luta pelos direitos dos Surdos, integrada por pessoas surdas e com objetivo de participar nas decisões da FENEIDA, direito que até então lhes eram negados. Finalmente em 1987, a FEINEIDA passou a ser chamada de FENEIS - Federação Nacional e Integração dos Surdos, com sede no Rio de Janeiro e regionais espalhadas pelo país, assim os surdos passam a defender mais intensamente a LS (Língua de Sinais).

A Lei 10.958 , de 27 e novembro de 2001 que nasce a partir do Projeto de lei $\mathrm{n}^{\circ}$ 900/99, do deputado Lobbe Neto - PMDB, torna oficial a Língua Brasileira de Sinais - LIBRAS ${ }^{4}$ e dá outras providências. Para o Governo do Estado de São Paulo:

Parágrafo único - Por recursos de expressão associados à Língua Brasileira de Sinais LIBRAS - entende-se comunicação gestual e visual com estrutura gramatical própria, cuja singularidade possa ser incorporada ao acervo cultural da Nação. [sic]

No Estado de São Paulo, o reconhecimento de Libras se dá pelo projeto de lei 900/99 que deu origem à lei 10.958, oito anos depois do estado de Minas Gerais, pela lei 10.379 de 10 de janeiro. O reconhecimento da estrutura gramatical indica que a Libras é, de fato, entendida pelas entidades que a defendem como uma Língua representativa da comunidade surda. Para Foucault (2010, p. 39):

Os discursos religiosos, judiciários, terapêuticos e, em parte também, políticos não podem ser dissociados dessa prática de um ritual que 
determina para os sujeitos que falam, ao mesmo tempo, propriedades singulares e papéis preestabelecidos.

Ou seja, podemos entender que essas leis traduzem a vontade de uma parte significativa da população, que consegue ver materializado na legislação um histórico de lutas. A Lei 10.098 de 19 de dezembro de 2000 (Federal), em seu artigo $1^{\circ}$ dispõe:

Art. 1o Esta Lei estabelece normas gerais e critérios básicos para a promoção da acessibilidade das pessoas portadoras de deficiência ou com mobilidade reduzida, mediante a supressão de barreiras e de obstáculos nas vias e espaços públicos, no mobiliário urbano, na construção e reforma de edifícios e nos meios de transporte e de comunicação.

Aqui a palavra em destaque é para chamar a atenção para as barreiras que ainda não foram superadas, além do termo que já não deveria ser utilizado nesta redação - portador - a lei não deixa claro que barreiras, no caso dos surdos, devem ser reduzidas, considerando a comunicação como única barreira. Porém, ao entendermos que a comunicação pressupõe uma troca de enunciados e, no caso de Libras, língua visual-gestual, é preciso considerar que não basta ensinar Libras a uma minoria de professores, mas pensar metodologias e estratégias diversas, bem como fomentar pesquisas na direção de um ensino de qualidade. Pois, o surdo precisa se articular com outros setores da sociedade e isso demanda a mobilização de uma série de habilidades ancoradas na leitura e escrita de uma sociedade oral.

A Lei 10.436, de 24 de abril de 2002regulamenta a $\mathrm{LBS}^{5}$ :

Art. $1^{\circ}$ É reconhecida como meio legal de comunicação e expressão a Língua Brasileira de Sinais - Libras e outros recursos de expressão a ela associados.

Parágrafo único. Entende-se como Língua Brasileira de Sinais - Libras a forma de comunicação e expressão, em que o sistema linguístico de natureza visual-motora, com estrutura gramatical própria, constituem um sistema linguístico de transmissão de ideias e fatos, oriundos de comunidades de pessoas surdas do Brasil.
Finalmente, a Língua de Sinais Brasileira ${ }^{6}$, e não poderia ser chamada de outro modo, é uma unidade, que se refere a uma modalidade linguística quiroarticulatória-visual e não oroarticulatóriaauditiva. Assim, há Língua de Sinais Brasileira, porque é a língua de sinais desenvolvida e empregada pela comunidade surda brasileira. Não existe uma Língua Brasileira, de sinais ou falada (CAPOVILLA, 2009).

Procurando nos textos oficiais, identificamos algumas expressões que precisam ser exploradas, para identificar se a Libras é de fato tomada como uma língua.

Considero que o problema começa aqui: Lei 10.436, artigo $4^{\circ}$ em seu "Parágrafo único: A Língua Brasileira de Sinais - Libras não poderá substituir a modalidade escrita da língua portuguesa" Então perguntamos: A Libras é uma Língua? Que a Libras não pode substituir a língua portuguesa até é possível entender com facilidade, ora, a comunidade dominante é oral, logo a comunicação precisa necessariamente passar pela língua oral, ou seja, a Língua Portuguesa, então o surdo precisa ser oralizado? Por que a tarefa de escrever português é tão difícil para o surdo? Não seria porque estamos diante de duas línguas distintas em suas formas de realização?

Mas, se a Libras é reconhecida como uma língua, que comporta estrutura gramatical e capacidade de comunicação e, deve ser incorporada ao acervo cultural da Nação, então não é lógico pensar que o surdo deva dela se utilizar para comunicar-se em seu território linguístico, inclusive por representação gráfica semelhante ao sistema de escrita da língua portuguesa?

Sendo assim, se Libras não pode ser registrada oficialmente, ou melhor, representada graficamente, pelo uso do Signwriting ${ }^{7}$ e a escrita surda universal, também, não substitui a Língua Portuguesa, onde está o reconhecimento dos recursos a ela associados? Quais seriam esses recursos? A representação do pensamento surdo a partir do empréstimo ${ }^{8}$ do português, ou melhor, da lógica de aproximação das duas línguas não pode ser aceita com um olhar diferenciado em respeito à estrutura sintática da escrita surda? Não seria Português também? Segundo Bagno (2011, p.107; 109) trata-se da "(...) língua realmente usada pelas camadas privilegiadas da população", enquanto que Norma Padrão diz respeito ao conjunto de regras claras e bem definidas para o uso da língua formal, 
portanto, os desvios da norma culta na escrita dos surdos não poderiam ser relevados em detrimento da singularidade da escrita do surdo no território da língua dominante que é oral? Não poderíamos considerar uma variedade linguística?

Dentro de seu território linguístico, o surdo não pode escrever em Libras, ou melhor, utilizar o Signwriting e não tem seu texto português surdo aceito como sistema de representação gestualvisual, análogo à representação gráfica pela escrita que representa a Língua Portuguesa. A propósito onde está escrito que não pode? Então, como diminuir a distância que separa a escrita surda da norma culta exigida pela sociedade ouvinte e em especial pela educação brasileira? Esta distância rende aos surdos muitos adjetivos que os desqualificam de muitos educadores, que tomam a forma composicional do texto surdo como limitação do sujeito diante do registro escrito da Língua Portuguesa.

Quanto às propostas de uma educação bilíngue, as discussões caminham no sentido de potencializar o ensino-aprendizagem do português. No entanto, muitas pesquisas apontam que, por mais que os discursos se revistam de novo, na verdade, o que temos vivenciado é uma insistência em ensinar uma língua oral a um sujeito que nunca será oral. Segundo Fernandes (2006, p.5)

Diante de todas essas evidências não há como negar que a filosofia oralista ainda reina absoluta, maquiada de um pseudobilinguismo que não oferece resistência ao seu reinado e tampouco contribui para a conquista da almejada cidadania bilíngue para os surdos.

Ainda, segundo a pesquisadora, o surdo se vê obrigado a seguir como usuário de uma língua sem status social, na condição de mancar entre a assimilação da escrita em português ou conforme Fernandes (2006) "relegados à cidadania de terceira classe".

Embora o Decreto 5.626, de 22 de Dezembro de 2005, que regulamente a Lei 10.436/02 em seu capítulo IV, artigo $14, \S 1^{\circ}$, inciso III, decrete que instituições federais deveriam prover às escolas professores para o ensino de Língua Portuguesa como segunda língua para pessoas surdas; o inciso IV garanta o atendimento especializado em turno contrário e os incisos VI e VII abordem inclusive as estratégias de avaliação da pessoa surda e dos mecanismos didáticos, parecem deixar claro que, apesar de reconhecida, não é a Libras que deve ser a língua primeira do surdo, assim, numa incoerência este capítulo do decreto valoriza a Língua Portuguesa. Não teríamos expressado um preconceito linguístico, no sentido de dizer uma coisa e propor outra?

Como a Legislação conceitua a Libras? Vejamos: A Lei 10.958 traz o conceito de Libras como língua gestual e visual (SP); a Lei 10.098 trata da acessibilidade, portanto, das barreiras comunicativas. (federal); a Lei 10.436 traz Libras como visual-motora (federal) e se constitui em sistema linguístico, mas o decreto 5.626 deixa claro que a Libras deve servir apenas de suporte para o domínio da Língua Portuguesa. Mais uma vez é possível constatar uma incoerência entre o que é posto como língua e barreira comunicativa.

Conforme o art. 20 do capítulo VIII do Decreto 5.296, as barreiras de comunicação precisam ser transpostas, mas até aqui o que se tem presenciado é a inclusão do ouvinte no mundo de Libras e, a partir daí, a imposição do português ao surdo.

Um surdo não é um ouvinte. E sua língua primeira, que pode ser a Libras ou simplesmente um gestual caseiro, não é compartilhada por todos na escola, às vezes, nem mesmo o surdo sabe Libras. Sendo assim, o que a leitura superficial de documentos nos faz perceber?

Entende-se que dar a conhecer o preconceito linguístico, que está camuflado não só na lei e nos decretos que a regulamentam, mas também em ações que parecem pretender apenas mascarar a grande distância entre duas línguas, se configura como que um remédio para todos os males, e a inclusão do surdo na sociedade/escola regular reside no simples fato de poucos professores saberem o mínimo da Língua de Sinais Brasileira, desconhecedores de questões linguísticas que permeiam a língua e a compreensão de que o português é a $2^{\mathrm{a}}$ língua para o surdo. Nas escolas especiais não é diferente, a língua de sinais não é a principal língua do currículo, o que evidencia que o oralismo é negado no discurso, mas não se consolida na prática educativa.

A Língua de Sinais Brasileira, assim como o Português, sofre variações regionais, de grupo etc., como se deve esperar da dinâmica das línguas orais. O trabalho do INES também é importante, pois existe a constante preocupação de melhorar e adequar cada vez mais os sinais às necessidades comunicativas e de expressão dos surdos. 
Os surdos salientam que suas maiores dificuldades se apresentam na hora de usar a língua portuguesa em discurso escrito. Assim, coloco em questão, também, a possibilidade de conceber a língua como:

- Libras: composta de sistema gestual + representação gráfica pelos empréstimos do português na estrutura surda.

- Por quê? Se a Lei reconhece Libras como sistema linguístico, então Sistema Linguístico conforme Saussure (1995, p.84):

(...) os significantes acústicos dispõem apenas da linha do tempo; seus elementos se apresentam um após outro; formam uma cadeia. Esse caráter aparece imediatamente quando os representamos pela escrita e substituímos a sucessão do tempo pela linha espacial dos signos gráficos.

Por que não aceitar a escrita do surdo, ou seja, a sua representação de língua que toma emprestado a grafia do português em outra estrutura, concebendo-a como outro falar, cujo registro dentro de alguns critérios, a partir da própria gramática da Libras, poderiam ajudar o surdo a se movimentar dentro da sociedade oral?

Este artigo pretende de alguma forma, levar para a pauta de discussões no cenário linguístico e educacional a questão da aceitação de escrita surda como a marca de uma língua de estrutura gramatical própria, mas que se ancora no português oral. Caso contrário, continuaremos a assistir ao tratamento dado à Língua de Sinais Brasileira por muitos, como apenas um suporte para fazer do surdo um usuário do português.

O surdo não poderá se fechar na Libras em todas as suas modalidades, pois está inserido em uma sociedade que ainda privilegia e exige o conhecimento e domínio da língua portuguesa oral e escrita. Ou seja, a Libras é apenas meio língua oficial. Já que no domínio escrito, os sujeitos são obrigados a se adaptar à Língua Portuguesa, ainda que hipoteticamente, poderíamos, sim, ter uma cultura surda escrita como temos as culturas indígenas, o que nos leva a outra questão: Tal cultura seria produtiva ao surdo num mundo de ouvintes?

Concluindo, um sujeito surdo só poderá ser denominado sujeito comunicativo dentro de uma comunidade falante que lê e fala, se conseguir se expressar no âmbito espaço-visual e escrito, unindo, consequentemente, o uso contínuo/simultâneo das duas línguas.

\section{Tudo está como era para estar: difícil}

Hoje, a educação trabalha com a palavra "meta", não importa o sujeito, mas a relação estatística para atingir a meta. O Estado olha para o corpo social e são criados os campos de controle, dentro desse corpo social, que precisa ser produtivo e consumidor. O currículo no Brasil é atravessado pelos discursos da governamentalidade e administrativo. O conceito Foucaultiano de governamentalidade (FOUCAULT, 2011) cunhado em sua fase genealógica, nos leva a compreender como o Estado, ao elaborar suas ações políticas, busca através de suas estratégias conduzir seus governados, com o objetivo de, à medida que tecem um tecido social, mantém sob seu controle, todas as camadas da sociedade. Assim, a indicação é de que esses modelos de governo evidenciados pelas políticas públicas vigentes são os que dão certo, mesmo que os relatos sejam de que as crianças ditas "especiais" estejam soltas dentro da escola e sem a devida atenção.

O currículo pode ser concebido como uma construção discursiva, campo de lutas e tensões, que a princípio, segundo Silva (2010), é posto de forma estrutural, mas quando começamos um questionamento, pensamos no sujeito. Assim, o teórico chama currículo de documento de identidade e formação do sujeito.

Estas discussões nos levaram a pensar, de fato, que sujeito se quer formar, pois, o sujeito da educação que temos hoje sendo formado nos parece ser aquele que domina outros conhecimentos. Toda a indústria da educação que se forma a partir desses novos sujeitos na sociedade fazem do "educar" nada mais do que uma ferramenta do capitalismo, ferramenta esta que se transforma e precisa se adaptar às novas realidades, contribuindo para esse a quem Foucault (2010) chamou de sujeito histórico social.

Parece mesmo que não há saída, por mais que se queira pensar uma formação humanística, incentiva-se cada vez mais os alunos ao sucesso, à transformação social pelo estudo e para a ascensão econômica, status, mas está errado? Não somos todos frutos de uma escola que também pregava isso? A inclusão, como tem sido posta nas escolas públicas, não estará negando ao surdo essa transformação social em função de um currículo que não contempla sua língua ainda que dentro de uma 
escola regular?

Muitas outras questões poderiam ser levantadas e discutidas, mas, por ora, gostaria de encerrar com um posicionamento a partir da leitura de "Do Governo dos Vivos" de Michel Foucault (2011) que nos deixa com as seguintes questões: como encontrar a metodologia ou caminho melhor para inserir o surdo na educação sem lhe dar oportunidade de acesso através de sua língua gestual com registro escrito? Talvez fosse possível encerrar esse tópico retomando a pergunta: como transformar ou adequar à tecnologia de si postulada por Foucault (2011) no caso do surdo, dentro de um currículo voltado a ele e feito a partir dele? Segundo Foucault (2004), as tecnologias de si, também chamadas de artes da existência:

devem ser entendidas como as práticas racionais e voluntárias pelas quais os homens não apenas determinam para si mesmos regras de conduta, como também, buscam transformar-se, modificar-se, modificar-se em seu ser singular, e fazer de sua vida uma obra que seja portadora de certos valores estéticos e que corresponda a certos critérios de estilo (FOUCAULT, 2004, p. 198-199).

Ao surdo cabe aceitar o que lhe foi imposto até que tenha meios de se autogovernar. Ainda assim, a subjetivação desse sujeito poderá acontecer tardiamente, pois embora sem essa percepção, o surdo é um corpo mutilado, humilhado pela falta de compreensão da língua oral da sociedade em que vive, direcionado por outros e despersonificado na escola por ser ignorado no atual sistema inclusivo.

Em relação a sua força de trabalho no mundo capitalista, ele é colocado dentro das empresas pela cota dos deficientes como mão-deobra barata e sem necessidade de grandes adaptações, não passando de forma de controle do Estado.

Como encontrar a metodologia ou caminho melhor para inserir o surdo na educação sem lhe dar oportunidade de acesso através de sua língua gestual com registro escrito?

\section{Tentando encontrar um caminho facilitador: valorizando a essência e não a aparência}

Para tentar responder tantas questões aqui formuladas, optou-se por trazer as considerações de Bagno (2007; 2011), entendendo que é possível pensar a escrita surda, como a representação de um falar, considerando também, que rotular a pessoa surda como incapaz de produzir o português escrito na norma culta é descartar que a sociedade em que vivemos atualmente, tão tecnológica e tão cheia de outras linguagens, não é capaz de agregar tal tipo de registro. Afinal, cabe-nos outra pergunta: será que não é possível para o surdo exercitar a escrita sem necessariamente atestar o domínio da norma culta? Com exceção do mundo acadêmico e de situações extremamente formais, sua escrita não pode ser encarada como uma variedade linguística?

As Línguas de Sinais, como já citado anteriormente, estão submetidas às mesmas variações das línguas orais, e o mais fascinante de tudo, é pensar que a língua está em constante movimento, por isso, essa discussão exige que retomemos o conceito de Sociolinguística ${ }^{8}$ uma vez que os falantes reais, surdos, devem ser considerados dentro e fora de suas comunidades linguísticas, e como já foi salientado, nem todos os surdos se utilizam da Libras, nem todos frequentam a comunidade surda, nem todos são oralizados, enfim, apesar da multiplicidade de sujeitos surdos que podem ser encontrados neste universo onde o grau de audição está em jogo, o comum entre estes sujeitos é o fato de que todos precisam aprender português para serem cobrados em seu registro escrito.

Ora, se a língua oral possuidora de tantas variedades, da mesma forma se apresenta em uma variedade de formas escritas em função das necessidades comunicativas de cada falante do português, então como exigir que o surdo falante de Libras, materialize seu pensamento em discursos escritos sem considerar a singularidade da Libras?

Parece confuso? É confuso mesmo! Essa é a ideia do artigo, provocar mais discussões em torno da produção escrita do surdo. Embora o espaço e o tempo para tantas reflexões possíveis sejam curtos, um exemplo de que os critérios para julgar a produção dos surdos dentro dos parâmetros atuais precisam ser revistos, é pensar, por exemplo, o estudo da variação em torno da marcação do plural nas sentenças. Se a variante produzida pela ausência do "s" em determinadas sentenças em falantes do português, por exemplo: "as bola é vermelha", temse nesta ausência um traço utilizado para relacionar as variantes sociológicas que podem indicar profissão, idade, educação, etc., o mesmo pode ou não significar a mesma coisa no caso da produção escrita surda. 
Por exemplo: na produção da sentença em Língua de Sinais que tem Sintaxe Espacial teríamos: EU TER CARRO DOIS ${ }^{9}$ (Eu tenho dois carros).

A organização da sentença acima é SVO, sujeito, verbo e objeto, e é considerada gramatical e possível na Língua. A mesma organização tende a ser transcrita para o português sem a flexão verbal e a marcação do plural no substantivo "carro" por surdos especialmente nas séries iniciais da educação fundamental. Apesar da inversão entre o quantificador e o objeto, é possível compreender a informação registrada, entretanto, o que as pesquisas têm mostrado é um esforço e uma discussão muito grande, em como produzir um ensino de português ao surdo que o leve à produção escrita na mesma organização da língua oral.

Bagno (2007, p.45), ao tratar do monitoramento estilístico, chama atenção para o fato de que os falantes vão construindo seu comportamento verbal através do convívio social; para o teórico, o monitoramento da escrita depende do contato com a leitura e da escrita. Assim, podese concluir que é do contato com a leitura de textos em português que o surdo conseguirá melhorar sua produção escrita, segundo Bagno (2007, p.46) “(...) O grau de letramento elevado também favorece, é claro, a produção de textos falados mais monitorados, em que a pessoa tenta reproduzir na oralidade mais formal traços característicos dos gêneros textuais escritos mais monitorados" [sic]. No caso dos surdos, estes leem em português, como segunda língua e produzem textos mais organizados na sintaxe da Libras do que do Português. Alcançar a produção escrita do português dentro da sintaxe e do padrão culto da língua tem-se convertido em extrema dificuldade, ora pelas diferenças entre as sintaxes das línguas, ora pela diferença discrepante entre os dois léxicos.

Diante destas dificuldades e do rótulo imputado aos surdos de que não "dominam o português", podemos voltar à questão da colonização da língua, ou seja, o português dos ouvintes reina soberano sobre uma língua, que diz a legislação ser reconhecida, mas que é aceita pela metade. As dificuldades do surdo em relação à escrita também repercutem na formação da identidade, pois é na escrita que o sujeito se revela, daí uma escrita precária, o preconceito linguístico que permeia a escola se apresenta de forma cruel, por atribuir ao surdo o seu fracasso diante da língua e dos conteúdos escolares. Neste caso, pode-se dizer que o bilinguismo parece se diluir dando lugar apenas para o português, enquanto a Libras e os falares surdos ficam, como podemos dizer, desprestigiados linguisticamente.

Assim, diante das questões que foram levantadas e das provocações em torno da aceitação ou não da escrita surda, coloca-se mais um elemento que precisa ser considerado: a escrita é a marca de um corpo. Segundo Coracini (2010, p.108), “(...) A escritura é da ordem da identificação", no mundo da escola, escrever está submetido à identidade da própria escola e, pelo tipo de inclusão que assistimos, trata-se de uma escola de identidade oral. Por isso, aceitar a escrita surda seria abrir espaço para outra identidade linguística que, talvez ao encontrar espaço para existir, facilitasse a compreensão da língua portuguesa, pelo ensino contrastivo das duas línguas, oral $\mathrm{x}$ visual, num mesmo espaço que, ao se conformar pela dominação do oral, poderia constituir-se no espaço de emancipação da escrita surda, ajudando o surdo a não se amedrontar diante do aprendizado da sintaxe do português em seu registro escrito.

Ainda é preciso voltar à primeira parte deste texto e acrescentar que muitas coisas aconteceram no sentido de atender às reivindicações dos surdos em relação à educação. Entretanto, há muito ainda por fazer. Coadunamos com o postulado por Bagno (2007, p. 19) para quem na educação existe uma confusão que surgiu na história entre língua e gramática normativa, pois segundo ele, gramática não é língua. Isto não significa também que não devemos aceitar qualquer produção escrita do surdo, mas levar em conta que as formas de registro escrito são diversificadas, tanto quanto os enunciados orais do português podem contribuir para uma visão menos monolíngue em relação ao português no Brasil. Afinal, existem muitos exemplos e estudos que sinalizam que os surdos comunicam-se e interagem muito bem, por exemplo, nos ambientes virtuais, ou seja, a necessidade de usar a norma culta surge em esferas de comunicação específicas, e nestas, pressupõe-se que o ouvinte ou surdo as acessam conscientes de que são espaços que valorizam a norma culta, assim, mais uma vez enfatizamos que o que está em jogo é desfazer a ideia de que o surdo não aprende escrever, mesmo porque qualquer língua escrita é artificial (BAGNO, 2007), necessita de treinamento, memorização, exercícios, etc.

Também, não é torturando o surdo na educação básica para que ele domine a norma culta, que este conseguirá ascender na sociedade, por isso, 
por trás dessa discussão tem muito mais, há de se discutir as políticas educacionais, a injustiça social e tantas outras mazelas, que deixam o surdo à margem da sociedade.

Espera-se que outros linguistas e pessoas interessadas na educação dos surdos colaborem com esse debate em torno da escrita surda. Pois, mais importante do que a discussão em torno de uma forma de escrita icônica da Libras, é aproveitar o que já existe de conhecimento sobre a organização da sintaxe da Libras e de como esta se realiza no texto escrito. Os trabalhos de Ronice Muller de Quadros (2006; 2007), entre outros linguistas, podem auxiliar muito, no sentido de ajudar na compreensão de como os surdos organizam a escrita. Assim, com algum conhecimento sobre a organização das línguas, talvez seja possível desfazer o preconceito linguístico em relação à produção do surdo.

\section{Conclusão: é preciso continuar a discussão}

Este artigo não teve a pretensão de formular grandes teorias, nem tão pouco propor ações radicais em torno do ensino do português ao surdo, mas refletir, sim, sobre como temos nos posicionado diante da produção textual do surdo. Assim, num exercício de rever a nossa prática, devemos nos perguntar se mesmo diante do fato de que os surdos apresentam grande dificuldade com a escrita, não estaríamos mais preocupados com a forma do que com a essência? Será que conhecer melhor a estrutura da Língua de Sinais não enriqueceria melhor nossas atividades na direção de trabalhar de fato com um ensino menos ditador da língua oral?

A experiência com o ensino de surdos e as leituras sobre as questões da produção textual, entre outras questões, nos levaram a pensar em como ajudar os surdos a superarem essas dificuldades, entretanto, depois de tanto refletir sobre o assunto, a conclusão que se chega é a de que nós é que não sabemos ler o que ele nos escreve. Ficamos presos às convenções do português e à ideia de que o surdo só conseguirá sobreviver no mundo oral se souber escrever bem. Não. Ele pode sobreviver sim, o que está em jogo é a compreensão e a leitura que ele faz do mundo. Quanto às formas de expressão, estas são muitas e podem ser aprendidas, desde que ele saiba que estas diferentes formas existem e de que os exercícios de escrita na escola são um elo com a sociedade, não sendo, portanto, uma forma de tortura e constrangimento. Não há fracasso da escrita que consegue produzir diante da idealizada pela escola, há uma escrita diferente, uma variedade linguística, que precisa ser compreendida por todos, para que também em nome dessa variedade, existam alguns parâmetros para que a produção possa ser considerada coesa e coerente, cabe, portanto, muitas outras discussões neste sentido.

\section{Notas}

1 Termo encontrado em documentos oficiais, mas que hoje não é mais utilizado é considerado um erro social, pois carrega um sentido de exclusão, abandono e incapacidade. Surdez e mudez são também patologias diferentes, uma não prevê a outra necessariamente. Também é considerada uma questão linguística por alguns.

2 Grifo nosso

3 Grifo nosso

4 A PLS 272/2014 que trata da Educação Especial em 17/12/2014 na Comissão de Direitos Humanos e Legislação Participativa sofreu emenda proposta pela relatora Senadora Lúcia Vânia com respeito à correta ortografia do Siglema que faz referência à Língua de Sinais Brasileira - Libras - com objetivo de adequar os documentos oficiais à Norma Técnica, através do Parecer 07017/2014 disponível

em http://www.senado.gov.br/atividade/materia/detal hes.asp?p_cod_mate=118617http://www.senado.g ov.br/atividade/materia/detalhes.asp?p_cod_mate $=118617-$ acesso em 31/07/2015

5 LBS - Língua Brasileira de Sinais - Tal denominação mencionada no documento gerou grande polêmica sobre a nomenclatura correta. Chamar a Língua de Sinais Brasileira utilizada pela $2^{a}$ maior comunidade linguística, os surdos, de LBS, poderia erroneamente designar a língua de sinais utilizada pela tribo Urubu-Kaapo. Situada ao sul do estado do Maranhão, essa tribo apresenta a proporção de um surdo para cada 75 habitantes, por isso todos utilizam a língua de sinais dentro da comunidade, facilitando a comunicação dos surdos com não surdos. Por isso, a língua de sinais reconhecida como $2^{\circ}$ idioma oficial do Brasil, passou a ser chamada de Libras.http://pt.wikipedia.org/wiki/L\%C3\%ADng ua_de_Sinais_Kaapor_Brasileira

6 "As línguas de sinais são consideradas línguas naturais e, consequentemente, compartilham uma série de características que lhes atribui caráter específico e as distingue dos demais sistemas de 
comunicação" (...) Quadros (2007, apud Peixoto, 2006 p. 222). Ocasionalmente, muitas das crianças usam da datilologia antes de ler ou escrever uma palavra, mas, independentemente de isto ocorrer ou não, existe a compreensão de que 26 das 46 configurações de mão que elas usam não para soletrar, mas para compor o sinal podem ser convertidas em letras e isso é considerado quando, diante de um sinal, ela precisa produzir uma escrita.

7 Escrita Universal de Sinais - Signwriting - para uma melhor compreensão a respeito desta escrita e sua aplicação na Educação de Surdos, a leitura do livro Análise Discursiva dos Estudos Surdos em Educação: a questão da escrita de sinais da professora Mestre Maria Salomé Soares Dallan (2013).

8 Segundo Orlandi (1986, p. 51), “A Sociolinguística toma a sociedade como causa, vendo, portanto, na linguagem os reflexos das estruturas sociais".

9 “(...) Esta é apenas uma das várias possibilidades de ordenação das palavras nas sentenças, mas que, apesar dessa flexibilidade, parece haver uma ordenação mais básica que as demais, ou seja, o ordem Sujeito-Verbo-Objeto" (QUADROS, 2007, p.139).

\section{Referências}

BAGNO, M. Preconceito linguístico: o que é, como se faz. 54 ed. São Paulo: Loyola, 2011.

Nada na Língua é por acaso: por uma pedagogia da variação linguística. 1 ed. São Paulo: Parábola, 2007.

BRASIL. Ministério da Educação. Secretaria de Educação Especial. Lei $\mathrm{N}^{\circ} 10.098$, de 19 de dezembro de 2000.

BRASIL. Ministério da Educação. Secretaria de Educação Especial. Lei No ${ }^{\circ}$ 10.436, de 24 de abril de 2002. Dispõe sobre a Língua Brasileira de Sinais LIBRAS e dá outras providências.

BRASIL. Ministério da Educação. Secretaria de Educação Especial. Decreto $N^{\circ} 5.296$ de 02 de dezembro de 2004.
BRASIL. Ministério da Educação. Secretaria de Educação Especial. Decreto $\mathrm{N}^{\mathrm{o}} 5.626$, de 22 de dezembro de 2005. Regulamenta a Lei $N^{\circ} 10.436$, de 24 de abril de 2002.

CAPOVILLA, F. C., \& RAPHAEL, W. D. Dicionário enciclopédico ilustrado trilingue da língua de sinais brasileira. São Paulo, SP: Edusp, 2009.

ECKERT-HOFF, B.M; CORACINI, M.J.R.F. Escrit(ur)a de Si e Alteridade no Espaço PapelTela. Campinas: São Paulo, 2010.

FERNANDES. S. Práticas de letramento na educação bilíngue para surdos. Curitiba/SED/SUED/DEE. 2006.

FOUCAULT, M. O uso dos prazeres e as técnicas de si. Foucault. Ética, Sexualidade, política. Ditos e Escritos 5. Rio de Janeiro: Forense Universitária, 2004.

A Arqueologia do Saber. $7^{\mathrm{a}}$ ed. Rio de Janeiro: Forense Universitária, 2010b.

A Ordem do Discurso. $20^{\mathrm{a}}$ ed. São

Paulo: Edições Loyola, 2010.

Do Governo dos Vivos. Curso no

Collège de France, 1979-1980 (excertos). 2 ed. São Paulo: Achiamé, 2011.

ORLANDI, E. $O$ que é linguística. 1. ed.; $9^{\mathrm{a}}$ reimpr. São Paulo: Editora Brasiliense, 1986.

QUADROS, R. M. de; SCHMIEDT, M. L. P. Ideias para ensinar português para alunos surdos. Brasília: MEC/SEESP, 2006.

QUADROS, R. M.; KARNOPP, L. B. Língua de Sinais Brasileira: Estudos Linguísticos. Porto Alegre. Artes Médicas, 2007.

SAUSSURE, F. de. Curso de Linguística Geral. $2^{\circ}$. ed. São Paulo: Cultrix, 1995.

SÃO PAULO: Lei 10958/01 | Lei $n^{\circ} 10.958$, de 27 de novembro de 2001 de São Paulo. Torna oficial a Língua Brasileira de Sinais - LÍBRAS e dá outras providências O GOVERNADOR DO ESTADO DE SÃO PAULO.

SASSAKI, Romeu. Inclusão: Construindo uma

Horizontes, v. 35, n. 2, p. 69-78, mai./ago. 2017 
sociedade para todos. Rio de Janeiro: WVA, 1997.

\section{Sobre as autoras}

Ruth Maria Rodrigues Garé é pós-doutoranda em Educação pela USF, doutora e mestre em Educação pela USF. Atua como docente no curso de Pedagogia e outras licenciaturas da PUC-Campinas, onde ministra Libras. Integra o Núcleo de Atendimento Psicopedagógico e Apoio aos estudantes com necessidades educacionais da USF.

Márcia Aparecida Amador Mascia é pós-doutora pela Universidade de Wisconsin-Madison em Educação, doutora em Linguística Aplicada pela Unicamp. É docente do programa de Pós-graduação Stricto Sensu em Educação da USF.

Recebido em dezembro 2016.

Aprovado em julho 2017.
SILVA, T. T. da (Org.) O Sujeito da Educação. $7^{\mathrm{a}}$. Ed. Petrópolis: Vozes, 2010 